\title{
La práctica social como expresión de humanidad
}

\author{
SOCIAL PRACTICE AS HUMANITY'S EXPRESSION
}

Napoleón Murcia (napo2308@gmail.com) Departamento de Estudios Educativos, Universidad de Caldas (Manizales, Colombia) ORCID: 0000-0001-9657-2086

Sandra Susana Jaimes (sjaimes@unisimonbolivar.edu.co) Grupo de investigación desarrollo humano, educación y procesos sociales, Universidad Simón Bolívar (Cúcuta, Colombia) ORCID: 0000-0001-93636101

Jovany Gómez (jgomez86@unisimonbolivar.edu.co) Grupo de investigación educación, ciencias sociales y humanas, Universidad Simón Bolívar (Cúcuta, Colombia) ORCID: 0000-0003-1958-7107

\begin{abstract}
Social reality is configured and permanently re-configured from the meaning societies give to the world. From these meanings, people shape their social order; their ways of being, doing, represent in the world, organizing in this framework their daily lives. It is established as a social practice as far as it acquires enough roots, significance and objectification to give a transformative sense to its social actors and their environment. The purpose of this article is to question some perspectives from which social practice has been set up, departing decisively from the functional dimension, showing the power of the concept of social practice in the human configuration as an expression of humanity from the social imaginary. The article analyses some trends in social practice, seeking to establish a synthesis as an expression of humanity; it confronts theories and support its proposal in the logic of social imaginary to overcome the practice as mere activity and place it as socio-historical and psychosomatic stage.
\end{abstract}

Key words: social imaginaries, social interaction, social ontology, social practice, social representations.

\section{Resumen}

La realidad social se configura y re-configura permanentemente a partir del sentido que las sociedades dan al mundo. Desde estas significaciones las personas configuran su orden social; sus formas de ser, hacer, representar en el mundo, organizando en este marco su vida cotidiana. Ella se establece como práctica social en la medida que adquiere el suficiente arraigo, significación y objetivación que les da un sentido transformador a sus actores sociales y su entorno. El objeto del presente artículo es abordar algunas perspectivas desde las cuales se ha configurado la práctica social, que se salen decididamente de la dimensión meramente funcional, y que evidencian la potencia de este concepto en la configuración de seres humanos como expresión de humanidad desde los imaginarios sociales. En el texto se propone un análisis de algunas tendencias de la práctica social buscando establecer una síntesis de consideraciones por las cuales esta adquiere una dimensión como expresión de humanidad; confronta teorías que la apoyan y soporta su propuesta en la lógica de los imaginarios sociales para superar la práctica como mera actividad y situarla como escenario socio-histórico y psicosomático. 
Palabras clave: imaginarios sociales, interacción social, ontología social, práctica social, representaciones sociales.

\section{Introducción}

Abordar la reflexión acerca de la práctica social y sus posibilidades es adentrarse en la discusión misma de la configuración de los seres humanos, en la definición de sus imaginarios sociales. Las formas en que esta posibilita a las personas y grupos sociales sus identidades, está en directa relación con su tradición y su historia, con los contextos y relaciones de fuerza, pero también con las formas particulares de ser/hacer, decir y sentir en el mundo. Tres tendencias se desarrollan en este análisis; una de ellas que visualiza las teorías de apoyo de algunos grupos de investigación que estudian esta temática, para quienes es preponderante su consideración como actividad derivada de las fuertes imposiciones sociales.

La segunda tendencia reflexiona sobre algunas posturas teóricas respecto de la práctica social, para quienes ésta es un espacio donde los sujetos se dinamizan, se recrean y construyen acuerdos. Dichos acuerdos se configuran en campos de fuerza y relaciones de poder que atraviesan este escenario en los diferentes contextos en los que acontecen.

Pero, más allá de reconocer que la práctica social está atravesada por los acuerdos, en la tercera tendencia, se genera una reflexión en torno al hecho de que la práctica social es ante todo una expresión de humanidad desde sus imaginarios sociales; lo anterior sustentado en que los acuerdos sociales se configuran desde las significaciones que las comunidades tienen sobre el mundo, el ser humano, la vida y la muerte y que definen las formas de ser/hacer, decir/representar de los actores de un grupo social.

Efectivamente, en una perspectiva que configura una forma diferente de ver la práctica social se ubica la teoría de los imaginarios sociales, teoría central desde la cual se asume el presente texto; en primer lugar, porque además de reconocer la práctica social como acuerdo social, la fundamenta como la expresión de todo ese cúmulo de sentimientos, creencias y convicciones que están en la base de la acción realizada y que dinamizan formas particulares de justificarla. Estas convicciones y creencias se condensan en significaciones imaginarias sociales que finalmente definen las fuerzas que determinan las formas de organización y los dispositivos para que esas formas definidas puedan llevarse a cabo.

\section{La tenuidad de los acuerdos}

La práctica social es asumida por la mayoría de los investigadores de este campo, como cualquier actividad recurrente que los seres humanos realizan. En esta consideración ella deviene de los acuerdos sociales previamente establecidos. Algunas perspectivas conceden a la práctica social el poder de generar organizaciones sociales y otras buscan relacionarlas con las representaciones sociales y por tanto dan el poder a los acuerdos sociales fundamentalmente simbólicos. En las perspectivas analizadas, todas ellas correspondientes a posturas de los grupos que la investigan, la práctica social es un saber hacer, bien como condicionante de lo social o bien que condiciona lo social, pero en ninguna de ellas se presenta como esa expresión de toda la humanidad de quien realiza dicha práctica social.

Camacho, por ejemplo, asume que la práctica social "se refiere a la actividad del ser humano, sobre el medio en que se desenvuelve. A través de las prácticas sociales el hombre da sentido a los problemas fundamentales de la ciencia sometiéndose a complejas relaciones entre ellos y su entorno" (Camacho 2006:133), perspectiva que evidencia un marcado interés técnico en la comprensión de la práctica social, 
el cual se expresa en el dominio que el ser humano genera sobre un escenario reducido de esta: la ciencia. Sobre este planteamiento cabe hacer preguntas como: ¿acaso la ciencia es el único escenario de la práctica social?, ¿acaso la práctica social sólo genera relaciones de sometimiento del mundo? Es importante considerar sin embargo que esa afectación a que se refiere es relativa a las matemáticas, campo en el cual desarrolla sus procesos de investigación. Pese a estos posibles cuestionamientos en torno al concepto emitido por el autor, toma como referencia a Abric, quien propone que en el estudio de las prácticas sociales se deben tener en cuenta dos factores: "las condiciones históricas, sociales y materiales en las que ella se inscribe y el modo en que se apropia el individuo o grupo concerniente" (2001:238); proceso en el cual los factores cognitivos, simbólicos y representacionales desempeñan un papel determinante. Es evidente que la perspectiva de Abric supera profundamente la práctica social como el mero hacer, pues junto a este, está la condición socio-histórica que imprime en el actor social una huella desde la cual realiza dichas prácticas, además éstas se inscriben en unos sistemas simbólicos configurados socialmente desde los cuales se fundamentan, dando también un papel importante a la dimensión particular del ser humano expresada en lo cognitivo.

Un grupo de investigación que coincide con la propuesta esbozada por Camacho, es el Centro de Estudios de Políticas y Prácticas en Educación (CEPPE) de la Pontificia Universidad Católica de Chile, que proponen estudios en prácticas de liderazgo directivo y aprendizaje. En un ejercicio esbozado según sus propios términos a guiar la investigación empírica, se muestra una profunda orientación hacia la práctica social como un saber hacer. Como elementos clave para una práctica de liderazgo efectivo, proponen: "1. Establecer direcciones, esto es proporcionar un propósito de carácter moral, que sirva de motivación para el trabajo del staff y los incentive a perseguir sus propias metas; 2. Rediseñar la organización, o sea establecer condiciones de trabajo que le permitan al personal el mayor desarrollo de sus motivaciones y capacidades y 3. Gestionar la instrucción, dinamizando procesos de enseñanza y aprendizaje en la escuela, lo cual implica la gestión de las prácticas de clase" (CEPPE 2009:25).

En un enfoque similar, para el grupo de enfermería de la Universidad Javeriana, la práctica social es asumida como práctica formativa orientada a poner en escena los conocimientos logrados en el proceso de formación en la carrera de odontología. En sus palabras "las prácticas sociales posibilitan la educación por competencias, entendidas no sólo como 'saber hacer en contexto', sino como lo que le compete saber y hacer a cada uno en términos de responsabilidad social" (Latorre et.al. 2009:99). El saber hacer articulado a la responsabilidad social imprime a la propuesta de este grupo una dinámica política de gran importancia, pese a lo cual no se articula la relación socio/histórica y particular (psicosomática) que está implícita en una práctica social.

La fuerza de lo social en la definición de las prácticas es también resaltada por el grupo que dirige el Aula de Sistematización de la práctica social de la Universidad de Granada, aunque asumida como un gran condicionante de ellas. Para ellos es considerada como el conjunto de conocimientos que enseñan el modo de hacer algo, ajustándose a la realidad y persiguiendo un fin útil. Incluso condicional al ejercicio de una facultad, según sus reglas, y la destreza adquirida con ese ejercicio. Proponen que debe existir un grado fuerte de fijación de la práctica social en el grupo de expertos-científicos, pues desde esta fijación se llevan a cabo los procesos que el grupo desarrolla. Esto lo explican asumiendo la práctica como posibilidad de contraste experimental de una teoría. Ella adquiere el carácter de social, dicen sus impulsores, cuando pertenece a los miembros que integran la sociedad; por tanto, en ellas confluyen conocimientos (científicos y técnicos) de la realidad concreta y de las actividades cotidianas (Grupo Universidad de Granada, 2015). Sin embargo, este grupo argumenta que es un proceso contradictorio, puesto que, pese 
a ser compartido con la población, desde estas prácticas los actores sociales construyen nuevas ideas y propuestas que llevan a la transformación de situaciones deseadas (es generadora de nuevas realidades).

En una perspectiva que critica el papel de lo social como condicionante de la práctica social, se ubica el grupo de investigadores liderado por Castro y otros, quienes desarrollan sus estudios sobre prácticas sociales. En ellos al contrario de las perspectivas descritas anteriormente, la práctica social es la que condiciona los grupos y sociedades humanas, a tal punto de asumir que "Dado que las sociedades humanas se asientan y definen a partir de determinadas prácticas sociales, sólo son, en cuanto a dichas prácticas" (Castro et.al. 1996:35). Consideran que, históricamente las prácticas han dado paso a sociedades discriminatorias, mostrando siempre una disimetría social entre clases, grupos de edad y sexo que han afianzado prácticas de explotación, opresión y violencia tanto física como simbólica. En síntesis, es la sociedad la que se configura desde las prácticas sociales. Ellas no son derivadas de la fuerza social, sino que condicionan los grupos sociales forzando sus dinámicas en una dirección totalmente heterónoma.

Rodrigues Leite da Silva et.al. (2012), aproximan la práctica como proceso de construcción social, en cuya perspectiva el estudio de la práctica social es asumido como estrategia para enfrentar procesos de gestión, de planificación y organización social; toman las prácticas sociales arraigadas a los micro y macrocontextos de las organizaciones y por tanto encarnadas en sus más profundas representaciones sociales, en razón a lo cual consideran como teorías de base para su comprensión las apuestas de Jodelet y Gilly asumiendo desde estos autores la naturaleza representacional de las prácticas sociales.

\section{Transitando por la práctica social como expresión de humanidad}

Como se muestra en el esbozo realizado, la mayoría de los investigadores asumen la práctica social desde perspectivas funcionales, o sea, como una actividad ejercida por los sujetos en cumplimiento de una función asignada. Si bien, algunas propuestas buscan el sustento en perspectivas que la reconocen como acuerdo social, finalmente este acuerdo lo configuran en una dirección: como una fijación que debe guiar los procesos de práctica social o como una imposición social que define dichas prácticas.

Pretendemos mostrar que la práctica social es algo más que una actividad, incluso que debe superar los acuerdos sociales desde los cuales se imponen unas funciones que los miembros de un grupo social deben cumplir y en el marco de las cuales debe realizar sus prácticas sociales, que tampoco, por sí mismas definen sociedades; antes que imposición, es una expresión de muchas cosas que se conjugan en el ser humano; es particularidad y socialidad, es creación y reconocimiento sociohistórico, es manifestación ética, estética, comunicativa, politica... es todo esto a la vez.

La práctica social debe ser considerada como expresión de toda la humanidad del ser humano representada en sus imaginarios sociales; esto es, que debe reconocer, en primer lugar, que el ser humano, quien realiza la práctica social es un ser socializado, o sea que cuando interactuamos con alguien, ese alguien es de por sí y por herencia social, un sujeto con un complejo entramado socio/histórico el cual influye en una práctica social.

En segundo lugar, que la relación con el mundo de quien realiza la práctica social está mediada por la dimensión simbólica e imaginaria que ese ser humano socializado ha configurado sobre el mundo, el ser humano, la vida y la muerte. O sea, quien realiza la práctica social se basa en esa dimensión simbólica / imaginaria del mundo, la cual subsume las otras dimensiones racionales y conjuntistas (ensídicas) (1). Si bien se debe reconocer la existencia de las dimensiones racional, ensídica y conjuntista del mundo, no es 
sobre ellas que el ser humano configura su realidad y define sus acciones e interacciones, pues cada una de estas acciones en interacciones corresponde a una significación que da sentido a dicha acción.

En tercer lugar, es importante considerar que, pese a esa fuerza de la historia y la tradición en la práctica social, los sujetos particulares matizamos los acuerdos sociales con nuestras propias significaciones sobre el mundo, el ser humano, la vida y la muerte. Los sujetos damos sentido particular a los acuerdos desde la imaginación radical que cada uno construimos, gracias a esas fuerzas psicosomáticas que permiten ver el mundo con nuestros propios lentes, lo que implica una radical creación, aunque en una relación magmática con lo social.

Y por último las prácticas sociales no son linealmente (unidireccionalmente) producto de nada ni generan condicionalmente nada, sino que estas fuerzas se presentan articuladas a manera de magmas, que configuran significaciones imaginarias sociales en las cuales se funden las formas de ser/hacer, decir/representar de los actores sociales que realizan una práctica determinada. En consideración a ello, pese a su capacidad de generar comportamientos e incluso grupos sociales, son también generadas desde ese magma de significaciones sociales que involucran lo racional, lo ensídico, lo particular (psicosomático) y lo social; pese a estar dinamizadas por los acuerdos sociales (en un aparente estado de inmovilidad respecto de cómo debe ser la práctica) en ella misma existe ebullición constante que hace posible permanentes transformaciones por parte de los sujetos particulares o grupos sociales que la realizan.

\section{Algunas proximidades teóricas}

La propuesta de práctica social como expresión de humanidad encuentra apoyo en teóricos de diferentes vertientes quienes ven en ella la conjugación de las experiencias de vida, como acopio de significaciones e interacciones que atraviesan relaciones efectivas de poder. Desde la realización práctica de Aristóteles, el saber práctico de Gadamer como experiencia lingüística manifestada en la fusión de horizontes, el coestar y la factibilidad del convivir expuesta por Heidegger, la perspectiva ontológica de Bourdieu y Giddens, los análisis en relación a las lógicas del poder de Jäger y Foucault, hasta las relaciones con la acción social de Schutz, expresan esa tendencia a considerar la práctica social como algo más que una mera actividad o acuerdo social.

Desde Aristóteles se comienza a asomar la posibilidad de considerar la práctica social como expresión de humanidad. En la perspectiva de conducta moral práctica de Aristóteles, la sabiduría no está meramente en la razón, sino en las posibilidades que las personas tienen de actuar conforme a ella. La realización práctica o Techné, que en sus palabras implica la maestría, no es posible sin la posibilidad crítica de la Phrónesis; o sea, sin la pregunta humana por ser mejor y por la expansión de toda la naturaleza humana en su realización (Areté).

Justamente, esta perspectiva es recuperada por Gadamer en la consideración del saber práctico, como saber-se. Saber no es el mero dominio de una técnica o el manejo de herramientas del hacer, es mucho más que esto; es saber desde adentro, saber desde lo que se es como totalidad, como sujeto del mundo, un mundo que no es para un sujeto único, sino que es con el otro y lo otro: saber-se. "El problema decisivo es, evidentemente, que esta ciencia práctica está relacionada con el problema general del bien de la vida humana, que no se ciñe, como las tejnai, a una esfera determinada" (Gadamer 1998:296). El bien de la vida humana no es un bien individual, es siempre en consideración a todo lo que se es en el mundo. 
En esta racionalidad Gadamer asume la comprensión hermenéutica como una categoría ontológica, y por tanto una práctica de naturaleza social que configura lo humano y que se configura desde la máxima expresión de lo humano: el lenguaje, de esta manera para el mismo autor, "el lenguaje sólo tiene su verdadero ser en la conversación, en el ejercicio del mutuo entendimiento" (Gadamer 1993:279).

La práctica social como experiencia lingüística puede entenderse como proceso de interacción social que más allá de un propósito de acción conjunta, construye identidad de grupo desde niveles de "comprensión como acontecer de sentido" (Gadamer 1993:217). La práctica como una experiencia hermenéutica que permite la construcción de sentidos desde procesos de interacción en torno a lo lingüístico, permite el acceso a las representaciones del mundo en ejercicio, de interpretaciones conjuntas; es decir, en la lógica de Gadamer (lógica discursiva), comprender es un proceso de relacionar el mundo que se habita con el mundo de la vida, en el cual no solo se vive, sino del que se hace parte desde los procesos de interacción lingüística y ese hacer parte involucra al ser con todo lo que es.

Al considerar que la comprensión hermenéutica es imposible sin la "fusión de horizontes" (en el cual se tejen tres horizontes de posibilidad: el horizonte social-cultural, histórico- social y particular), Gadamer incuba en esta perspectiva la práctica social como expresión de humanidad. Lo anterior, en tanto el horizonte en Gadamer, hace referencia a "algo en lo que hacemos nuestro camino y que hace el camino con nosotros. El horizonte se desplaza al paso de quien se mueve... Comprender una tradición requiere sin duda un horizonte histórico" (Gadamer 1993:372, 375). La práctica comprensiva es llegar a fundir esos horizontes en cada momento y en cada escenario posible, pues en sus propios términos, dado que somos del mundo, nuestra experiencia en este cambia constantemente, cada vez que realizamos esta fusión lo hacemos de forma diferente, de acuerdo a como estamos viviendo ese mundo, de acuerdo al horizonte posible de fusión.

Justamente el considerar los planteamientos Aristotélicos de la filosofía práctica como ese saber del ser humano que no se deja llevar por los impulsos, en consideración a que las acciones se definen con la preponderancia de la razón y por tanto involucra la totalidad del ser, llevó a Gadamer a suponer que la praxis no es una mera actividad funcional del ser humano, un conjunto de acciones particulares y caprichosas, sino que ella se inscribe en el marco de las racionalidades universales, pues la práctica es ante todo un saber ético que se descifra en las lógicas del deseo y la posibilidad social del mundo de la vida. La universalidad práctica dice Gadamer, implica que "está implícita en el concepto de racionalidad (y en su carencia) nos comprende a todos, y totalmente" (Gadamer 1998:316).

Este abordaje de la práctica social ubica la comprensión de dicha práctica más allá del hacer con otros, al ser con otros, así lo declara Heidegger: "El 'ser con' y la facticidad del 'ser uno con otro' no se fundan por ende, en un 'ser juntos ante los ojos' de varios 'sujetos'” (Heidegger 1977:137). Sin embargo, el estar solo "entre" muchos tampoco quiere decir, por su parte, en relación con el ser de los "muchos", lo que implica una perspectiva ontológica desde la cual la configuración de lo humano al pasar del plano personal al colectivo genera arraigo y movilización de acciones conjuntas de sentido común y no individual; esta característica aleja cualquier posibilidad alienadora como movilización heterónoma hacia un ejercicio de sentido autónomo y por ende dinamiza una expresión de libertad que privilegia las necesidades, principios, metas y acuerdos definidos en conjunto; es decir, lleva a definir un sentido del ser con el otro. Por lo anterior, esta racionalidad es altamente humana en tanto parte del reconocimiento del otro que proyecta el crecimiento del otro como persona y la posibilidad de transformación positiva. 
Una consideración similar aflora en los desarrollos de Bourdieu y Giddens; según Jaramillo la práctica social reconocida tanto en Bourdieu como en Giddens "debe comprenderse en el marco de una perspectiva ontológica que se orienta a descubrir, de manera imbricada, tanto la génesis social del ser y el obrar humanos, como la reproducción y la transformación del mundo social" (2012:130). Donde dejan ver su posición frente al mundo social como "un escenario dialéctico de producción y reproducción constante de acciones y estructuras que dan forma y contenido a las prácticas sociales" (Jaramillo 2012:130); con lo cual la práctica social trasciende los meros escenarios de acción funcional y se orienta hacia cuestiones representativas de la totalidad humana, que involucra el ser como sujeto de comunicación y reflexión; la práctica como expresión del ser.

Justamente para Giddens el concepto de práctica social hace referencia a todas aquellas actividades humanas sociales que operan en el tiempo y en el espacio, y que están atadas a registros reflexivos y discursivos producidos por los mismos agentes sociales. Entre tanto para Bourdieu es la representación de las relaciones de poder simbólico anclado a unos intereses concretos, como en el caso de la ciencia, cuyos intereses están definidos por las comunidades científicas. Las prácticas sociales para Bourdieu se dan en función del hábitus intelectual, que le confiere justamente la unidad y coherencia que se requiere para proyectarse como una expresión de humanidad: "el habitus demanda ser comprendido como una gramática generadora de prácticas acordes a las estructuras objetivas de las que es producto; la circularidad que preside su formación da cuenta, por una parte, de la producción de regularidades objetivas de comportamiento $y$, por otra, de la modalidad de las prácticas que descansan sobre la improvisación y no sobre una ejecución de reglas" (Bourdieu 2007:44). Así, si bien el hábitus genera prácticas, no constituye la práctica por sí sola, ya que la modalidad de dichas prácticas permite la expresión del ser sin condicionamientos que lo limiten.

En la lógica de Foucault, las prácticas discursivas también se convierten en escenarios constituyentes de lo social y las subjetividades. En tanto dispositivos discursivos son escenarios donde se contribuye a la estructuración de las relaciones de poder de una sociedad. Los objetos discursivos se forman en la relación presencia y ausencia de las prácticas discursivas que aparecen como enunciados sobre una cuestión determinada. Las continuidades y discontinuidades de estos enunciados aparecen dispersos en diferentes discursos, escenarios y tiempos, pero siempre ligados a unas condiciones socio-históricas que hacen posible que estos aparezcan o no. "Los enunciados diferentes en su forma, dispersos en el tiempo, constituyen un conjunto si se refieren a un solo y mismo objeto. El conjunto de enunciados no se refiere a un solo objeto ni están en un solo escenario" (Foucault 2002:47). De forma similar, en Jäger las prácticas discursivas son poseedoras y depositarias de un saber que, al estar presente en las acciones e interacciones de las sociedades, tienen fuerza de realización: "ejercen el poder porque transportan un saber con el que se nutre la conciencia colectiva e individual" (Jäger 2003:69). En su perspectiva, la importancia de las prácticas discursivas sobre los grupos sociales es tal, que para lograr que una realidad social sea significativa, es necesario que ella esté construida por los discursos.

Conforme con lo expuesto hasta aquí, en términos de las aportaciones a una práctica social como expresión de humanidad, es de considerar que, además de otras perspectivas aquí no consideradas, es de enorme valor la propuesta de Alfred Schütz al asumir que las realidades sociales son siempre fenomenológicas y que ellas corresponden a esas coordenadas de la "matriz social" (Schütz 2008:18). En la lógica de Schütz, la práctica social se insinúa cuando hay una acción, esto es, cuando se proyecta una conducta de manera autoconsciente; a diferencia del fantasear, la acción está dotada de propósito, a lo cual se conoce como afectación. La afectación es la que permite las justificaciones de las acciones. Entre tanto el acto corresponde a la acción realizada. En tal sentido, la acción se origina en la conciencia del 
actor. De ahí que las razones en el marco de las cuales los sujetos justifican las actuaciones, cobran sentido en el análisis de los contextos sociales e históricos que han rodeado la vida de las personas que actúan, lo anterior amparado en la base central de su teoría: la presunción o pre-suposición, fundamento sobre el cual se configura el mundo de la vida, el mundo del sentido común.

Pero este proceso es más complejo que la sola realización de una acción que corresponde a las coordenadas edípicas y condicionamientos de lo social, pues en términos del autor, cuando el hombre configura ese mundo del sentido común, ese mundo de la vida, acude también a su estado particular de formación y desarrollo, eso que las microsociologías han determinado como de rango familiar y que Schütz reconoce como la situación biográfica, al definir que "es la sedimentación de todas las experiencias previas del hombre organizada en el patrimonio corriente de su acervo de conocimiento a mano, y, como tal, es su posesión exclusiva, dada a él, sólo a él. Esta situación biográficamente determinada incluye ciertas posibilidades de actividades prácticas o teóricas futuras (...) a las que denominaremos propósito a mano" (Schütz 2008:41). Esta situación de vida del actor social es la que permite que se sitúe como un sujeto particular ante las racionalidades del sentido común, en lo que le permite asumir esas generalidades de lo histórico social. De forma particular, desde ellas se matizan las realidades sociales con las particularidades creativas de los actores, algunas de las cuales controvierten las lógicas definidas como normales.

Justamente, otra categoría central en la consideración de las realidades de la vida cotidiana de Schütz es el acervo de conocimiento a mano que el actor social posee a la hora de realizar las acciones o prácticas sociales. La verdad es que la situación biográfica, esa condición que le permite al actor ser sí mismo, lo dota, además, de un conjunto de tipificaciones regularmente devenidas del mundo del sentido común, desde cuyo caudal realiza las acciones; a decir de Schütz, estas tipificaciones surgen de una estructura social. En este sentido, la práctica social es manifestación de la acción proyectada, que como lo establece el mismo Schütz surge de la conciencia; pero aquí se trataría de una conciencia colectiva sobre el mismo mundo de la vida, que dinamizada en unos motivos se convierte en acción. Así en la voz del autor: "los motivos y los objetivos forman parte de la conducta del otro de forma tan ineluctable como de la nuestra" (Schütz 2008:23). En la perspectiva del autor, la práctica social implica entonces, la comprensión de un mundo intersubjetivo, en tanto lo que me motiva a realizar algo, o a no realizarlo, está siempre relacionado con las normalidades del mundo de la vida.

\section{La correspondencia con la teoría de los imaginarios sociales}

En los esbozos realizados hasta aquí, se han analizado formas de asumir la práctica social por grupos de investigación en este campo, se han propuesto racionalidades que reconocen la práctica social como razonamiento ético y por tanto ubicado en las universalidades de la razón moral práctica (Aristóteles) o racionalidades que la asumen como escenarios de configuración del ser humano asociándola con el saber práctico de la hermenéutica comprensiva y con ella la fusión de horizontes que involucra todo el ser humano reflexivo (Gadamer), como escenario de configuración social (y por tanto ontológico) orientado a descubrir la génesis del obrar humano en el marco de sus reproducciones de poder (Bourdieu y Giddens), o como escenario de construcción de objetos discursivos (Foucault) y finalmente, como expresión de la vida cotidiana y la franca influencia del mundo pre-configurado (Schütz). En esta sección se presenta una propuesta, que sustentada fundamentalmente en la teoría de los imaginarios sociales y en especial en la perspectiva de Cornelius Castoriadis, argumenta la posibilidad y pertinencia de esta teoría en la configuración de la práctica social como expresión de humanidad. 
Si bien la correspondencia de la práctica social con las aportaciones teóricas precedentes se configura desde la perspectiva de la inmanencia, lo cual define la expresión de la humanidad del ser humano, en la racionalidad de los imaginarios sociales se encuentra una enorme fuente de posibilidades para sustentar y ampliar dicha razón. Lo anterior, por cuanto la base de su consideración es la imbricada relación que existe entre las dimensiones del ser humano y el mundo, que a manera de magma se unen para representar la complejidad de las realidades sociales. Esto es, que la realidad social y humana se configura en medio de la permanente efervescencia que funde la dimensión ensídica del mundo (aquella que permite agrupar, categorizar, clasificar...) con la dimensión imaginaria (definida por el cúmulo de motivaciones, convicciones y creencias fuerza), la dimensión social con la particular (psicosomática), la socio-histórica con la dimensión de creación radical, el caos con la organización parcial. Pese a esta fusión desde la cual aparecen las formas de ser común (las formas de actuar en el marco de lo normalizado) en el fondo de la realidad social siempre están fundiéndose nuevas cuestiones que proponen cada vez novedosas realidades. De ahí que la teoría de los imaginarios sociales es ante todo la teoría de la total y constante creación; creación de sujeto y de sociedad, tal y como lo expresa Castoriadis en el ser y el tiempo y a lo largo de toda su obra y lo analiza con gran suficiencia Franco Yogo (2003) en su escrito sobre Castoriadis.

Los imaginarios sociales son considerados en esta propuesta como "ese cúmulo de convicciones, motivaciones y creencias/fuerza que las personas/sociedades configuran respecto del mundo, el ser humano, la vida y la muerte, desde cuyas significaciones se generan los acuerdos sociales sobre las formas de ser/hacer, decir/representar. Desde ellos se configuran esos esquemas sociales que guían sus comportamientos y formas de habitar el mundo, por ellos existe en las sociedades y personas los conceptos ético/morales, estéticos, políticos, comunicativos y teóricos que permiten asumir las realidades de una o de otra forma" (Murcia 2011:34).

Su naturaleza es intangible, pues "no se presentan como una pragmática ordenada de inteligibilidad del universo, sino como una composición relativamente libre e irreductible, en la medida que no ha de rendir cuentas a ningún tipo de racionalidad y en el hecho de que este fundamento reside en la libertad relativa de creer; yo creo que las cosas son así (...) tiene que ver con la creencia y la fe" (Baeza 2000:22).

El imaginario social es, en términos de Tylor, un amplio entendimiento entre un colectivo en particular, sobre el modo de concebir la vida social, lo que implica que los imaginarios son acuerdos sociales en las formas de creer el mundo social en el marco de los cuales se hace válido o no, las acciones e interacciones en ese colectivo: "Existen importantes diferencias entre un imaginario social y una teoría social. Adopto el término imaginario 1) porque me refiero concretamente a la forma en que las personas corrientes 'imaginan' su entorno social (...) 2) el imaginario social es la concepción colectiva que hace posibles las prácticas comunes y un sentimiento ampliamente compartido de legitimidad" (Tylor 2006:36).

Pero ante todo, los imaginarios sociales definen las formas de ser/hacer en el mundo y de decirlo y representarlo. Es tan potente esta condición en los imaginarios sociales, que Pintos considera que estos son, en realidad esquemas de inteligibilidad y plausibilidad social: "Mi propuesta consiste en denominar a esta compleja agencia social: agency-Imaginarios Sociales, que serían esquemas construidos socialmente que estructuran en cada instante la experiencia social y engendran tanto comportamientos como imágenes reales. Lo que sea creíble como función de la plausibilidad no se define por la aportación de argumentos ante un público con capacidad de discusión sino por la construcción / deconstrucción de determinados imaginarios sociales, que permiten la elaboración y distribución generalizada de instrumentos de percepción de la realidad social construida como realmente existente" (Pintos 2002:28). 
De forma similar, Castoriadis asume que desde las significaciones imaginarias sociales las instituciones definen sus acuerdos funcionales, esto es, esas dinámicas instrumentales que guiarán las acciones e interacciones de las personas que pertenecen a dicha institución y desde las cuales se definen también los dispositivos para que dichas funciones se puedan llevar a cabo. Sin ellas es imposible la subsistencia de estas instituciones, "lo imaginario social existe como hacer|representar lo histórico- social" (Castoriadis 1989:140). Una institución, dice Castoriadis, "consiste en ligar a símbolos (a significantes) unos significados (representaciones, órdenes, conminaciones o incitaciones a hacer o a no hacer, unas consecuencias, unas significaciones, en el sentido lato del término) y en hacer valer como tales, es decir, en hacer valer este vínculo más o menos forzado para la sociedad o el grupo considerado" (Castoriadis 1983:201).

Lo anterior significa que en realidad las prácticas sociales no son otra cosa que la expresión de los imaginarios sociales o sea de esas convicciones, motivaciones y creencias fuerza que constantemente construimos los seres humanos y que como tal compromete a la sociedad en su conjunto. Esto, puesto que la sociedad es la gran institución creada por el ser humano, dice Castoriadis, pero no solo crea la sociedad sino las condiciones y dispositivos para que ella funcione: "ella toma existencia según el modo de ser del para sí, y cada sociedad es un para sí (...) crea su mundo propio y para ella nada puede tener sentido o existir, siquiera sino entra en su mundo propio, en la forma en que este organiza y dota de sentido a lo que ingresa en él" (Castoriadis 1998:22 y 26).

Esto implica varias consideraciones a tener en cuenta a la hora de referirse a una práctica social. Una de ellas, ya mencionada, es la consideración central de que en una práctica social se conjuga a manera de magma todo lo que somos en términos de la experiencia socio-histórica como movimiento constante de acuerdo/transformación. De aquí que como lo retoma Arribas: "La dimensión ensídica y el imaginario pertenecen a un continuo de prácticas sociales. Nuevas formaciones discursivas emplean elementos de las antiguas, las combinan y crean prácticas distintas" (Arribas 2008:122). Evidentemente, la racionalidad en la cual se funda la teoría de los imaginarios sociales descansa en los magmas; esa figura que el mismo Castoriadis consideraría como eje de su propuesta de investigación desde la cual se explican las estrechas y complejas relaciones que definen los imaginarios sociales en diferentes dinámicas. Ellos, como sucede con los magmas, se configuran desde la fusión de diferentes cuestiones; aquellas devenidas de la fuerza social y las propias de la psique: "La psique y la sociedad encuentran un apoyo mutuo para poder existir, ambos son a modo de un magma" dice Franco Yogo al exponer la teoría de los magmas en la lógica de los imaginarios sociales castorianos (Yogo 2003:110).

Justamente, la figura del magma es tomada por Castoriadis para referirse a un modo de coexistencia en fragmentos de múltiples organizaciones lógicas, pero no reductible a una organización lógica. La noción de magma es aplicada tanto a la psique en tanto expresión de la imaginación inicial, sin referencia (radical), como a la sociedad en tanto magma de significaciones sociales. Franco Yogo lo explica desde la fusión entre la particularidad y la fuerza social: "La subjetividad asumiendo que ella es producto de la incorporación de significaciones imaginarias sociales creadas por el colectivo anónimo de los sujetos a partir de su imaginario social instituyente. El sujeto deviene dando a su pasado y a su porvenir un sentido, eligiendo un proyecto identificatorio y una interpretación de su historia reelaborada sin cesar" (Yogo 2003:15).

La complejidad de las relaciones que se dan en lo social también es vista por Buber en Theunissen, al considerar "la ontología de lo entre" que trasciende la postura Heideggeriana del Dasein y se ubica desde la mutualidad entre el yo y el tú, en la esfera de la subjetividad conjunta y la esfera dialógica del ser que dan sentido y mueven la acción (Theunissen 2013:291). 
La práctica social en esta lógica no es una consecuencia de nada, ni es tampoco el origen de nada, pues está articulada a la vida del ser humano como manifestación de su posibilidad de ser/hacer y decir/representar en el mundo. Hace parte del ser humano y como tal lo constituye; siendo origen, pero también originando, siendo creación, pero también creando, siendo imaginación y a la vez acción. Si las realidades sociales son magmas de relaciones y significaciones, lo son también, y de hecho sus prácticas sociales, pues en ellas se funde lo psicosomático, con lo histórico-social, lo genético, lo cognitivo en una sustancia que se evidencia en acción. Una sustancia que no es posible separar, que se sabe de sus componentes, pero que dada su complejidad es irreductible a una dimensión, sea ella racional, ensídica e incluso imaginaria.

Una sustancia que toma referencias de lo normalizado del mundo de la vida siguiendo pactos sociales previamente elaborados, pero que, al mismo instante, reconoce las alteraciones de lo particular, los matices que cada actor social pueda otorgar a estos acuerdos definidos y reacciona a estos matices reconfigurándose en cada instante, como acuerdo parcial y por tanto dinámico.

Evidentemente, en estudios realizados por uno de los autores del texto acerca de los imaginarios sobre Universidad y sobre los maestros en formación, se nota con suficiente claridad que estos imaginarios siempre se movilizan en los bordes de lo establecido por lo institucional (imaginarios instituidos), y que antes de seguir una línea de configuración, ellos se expresan en multiformidades y polifonías que a la vez se transforman para adaptarse y actuar en la vida cotidiana. Una práctica social como consolidación de este magma de significaciones, entonces, es articulación compleja de múltiples dimensiones del ser humano (ser social/histórico y psicosomático, lo ético, estético, comunicativo).

Una segunda consideración está en la capacidad creadora del psicosoma que, además de asumir la naturaleza socializada del ser particular, dispone de la irreductible posibilidad de crear sus propias significaciones. En la figura de los magmas como en lo social, las producciones son de constante y permanente transformación. Pese a que en la superficie existan algunas formas aparentemente sólidas, ellas no son más que figuras temporales que se están transformando gracias a la permanente ebullición o efervescencia que existe en su interior. En los imaginarios sociales lo que se solidifica es en realidad la creencia y convicción sobre el mundo, esa sanción social que define una convicción/creencia como válida o no. O sea un tipo de imaginarios naturalizados y desde los cuales se generan los acuerdos funcionales que hacen posible la institución. Desde ellos se realizan las prácticas sociales más comunes en la institución (prácticas hegemónicas). Castoriadis denominaría a estas significaciones consolidadas: imaginarios instituidos.

Efectivamente, los mismos acuerdos sociales traen consigo desacuerdos respecto de las prácticas sociales que se asimilan a las efervescencias magmáticas. Estas efervescencias en lo social están dadas por otro tipo de imaginarios: los radical/instituyentes; esos imaginarios propios de la psique-soma, que a decir de Castoriadis son irreductibles a la sanción social, en su autonomía, permiten matizar el acuerdo social y generar la movilidad constante. Gracias a estos imaginarios las sociedades e instituciones se transforman y modifican de forma permanente: "Una sociedad se conserva gracias a su incesante alteración" (Castoriadis 1989:66). El tiempo mismo es institución social, de ahí que lo histórico social es imaginario radical, porque es transformación, creación, cambio, irrupción de imaginarios instituyentes e instituidos.

De forma evidente, la teoría de los imaginarios sociales, pese a considerar el mundo de la vida en el marco de los posibles acuerdos que definen las formas de ser común en la vida cotidiana, asume lo no común como la esencia de las dinámicas sociales, en tanto cualidad que no solamente se crea a sí misma, sino 
que crea las condiciones para su gestación: la sociedad misma es una creación, así como lo es el ser humano particular que la configura y las prácticas que el ser humano dinamiza: "Tanto en lo que concierne a las partes que pone como a las relaciones que establece entre esas partes y entre ellas, y el todo, es en cada momento una creación de la sociedad en cuestión. Y esta creación es génesis ontológica, posición de un eidos, ya que lo que de tal manera se pone, establece e instituye cada vez, y que por cierto es vehiculado por la materialidad concreta de los actos y las cosas, supera esa materialidad concreta y todo eso particular, es tipo que permite una reproducción indefinida de sus instancias, las cuales únicamente son en general y son lo que son en tanto instancias de ese tipo" (Castoriadis 1989:31).

El eidos es la significación subjetiva que se articula al objeto creado. No es que el objeto tenga dentro de sí la función, diría Searle, sino que el ser humano genera el objeto o fenómeno, en el marco de las funciones agentivas (o sea que él mismo asigna). Por ejemplo, un cuaderno es ese tipo de eidos creado, como lo es también una palabra cualquiera; ambos dependen de la funcionalidad interna que cada sociedad haya considerado, pero también y a la vez dependen de su propia naturaleza sustantiva; por eso, pese a que el cuaderno es creado con una función agentiva designada por lo social, en muchas ocasiones su uso puede tomar otras funciones derivadas de las significaciones psicosomáticas o particulares de quien lo usa. En consideración a lo cual, las prácticas sociales que en su uso se derivan, pese a estar de cierta forma sujetas al eidos, se configuran desde las significaciones imaginarias sociales, las cuales permiten transformar constantemente la función asignada.

Esta creación es a la vez clausura y apertura, organización y caos; pero sobre todo es orientación imaginante y creativa del ser humano. Una creación que, pese a su materialidad, lleva condensada una acción según las significaciones imaginarias sociales que la hacen posible y permisible. La materialidad de la cosa creada no se expresa por la cosa misma; el cuaderno, el vaso, o la palabra creada no están en papel de neutralidad, su naturaleza eidética no define ni la creación ni su funcionalidad, pues pese a que se genera atendiendo a ella, depende de la sociedad y sus significaciones; es el ser humano el que le da la utilidad en el marco de las funciones asignadas y estas funciones dependen de las significaciones sociales.

Porque, como lo manifiesta Castoriadis, el imaginario radical "es el núcleo de ser y del modo de ser de la psique humana singular por un lado, y de lo histórico social, por otro. Porque hay imaginario radical hay institución; y sólo puede haber imaginario social en la medida en que se instituya" (Castoriadis 1998:12). De esta manera la práctica social estaría constituida por dicho imaginario radical.

En esta racionalidad, la creación define la ontología del ser, no solo como ser humano que es, sino y sobre todo como ser social que se configura. Por esto, la creación en la práctica social no es una casualidad ni se da ocasionalmente, sino que es su caracterización, su esencia, la determina y se congrega como unidad magmática que funde múltiples dimensiones y polifonías.

Así, más allá de considerarse las significaciones sociales como representaciones individuales, para Castoriadis son "aquello por medio de lo cual y a partir de lo cual los individuos son formados como individuos sociales con capacidad para participar en el hacer y en el representar/decir social" (1989:566); he ahí la capacidad ilimitable de la teoría del imaginario social, al considerar la dimensión eidética del mundo como de gran valor en las realidades sociales, pero subsumida por sus significaciones imaginarias sociales. Por esa dimensión desde la cual se logran los acuerdos funcionales sobre las formas de ser/hacer y decir/ representar en y el mundo y en consideración a ello de actuar en el mundo: es la práctica social. 
Justamente, esta es la tercera consideración que una práctica social como expresión de humanidad debe plantear. La dimensión del mundo desde la cual se realiza la práctica social es la dimensión simbólica/imaginaria la cual se configura en relación como las otras dimensiones del mundo (la dimensión racional y la dimensión ensídica y todo lo que ellas contienen): "Todo lo que se presenta a nosotros, en el mundo social-histórico, está indisolublemente tejido a lo simbólico. No se agota en ello. Los actos reales, individuales o colectivos -el trabajo, el consumo, la guerra, el amor el parto- los innumerables productos materiales sin los cuales ninguna sociedad podría vivir un instante, no son (ni siempre ni directamente) símbolos. Pero unos y otros son imposibles fuera de una red simbólica" (Castoriadis 1983:201).

En esta racionalidad, las prácticas sociales no son otra cosa que la expresión de la humanidad del ser que las realiza, por tanto, así la práctica se ejecute como un actuar mecánico, en ella está reflejada la forma de vida, la historia particular, el estado de actor en el momento de la acción (el estado de ánimo, el estado físico, social, técnico y otros estados), los ordenamientos genéticos y sociales, ese acervo de conocimiento que ha sido cooptado como tipificación social o que ha sido adaptado por el sujeto, pero también y con gran fuerza esa particularidad creativa que le permite crear constantemente sin tomar referencia alguna. Esto es, la práctica social es la expresión de la persona que la realiza (como persona socializada), con todo lo que la persona fue, es y está por ser.

De hecho, la misma sociedad es como lo propone Shotter "un flujo turbulento de actividad social continua" (2001:35), y ese flujo es manifestación de lo que la sociedad ha configurado como su forma de vida, bien sea mediante figuras ya construidas, más o menos estables, o como significaciones caóticas y móviles que imprimen la dinámica de la permanente construcción social.

Es en este núcleo donde se define lo que el autor denomina el "conocimiento de tercer tipo", un conocimiento que se tiene tanto desde adentro de una situación social como "desde adentro de sí mismo, como ser humano y como miembro socialmente competente de una cultura" (Shotter 2001:38). Bajo esta consideración se reconoce entonces la práctica social como la manifestación de todo lo que el ser humano es, puesta al servicio de una sociedad en la cual la acción no responde a un interés particular sino a un interés de tercer tipo, porque "no es ni el tuyo ni el mío", como lo propone el mismo Shotter. En esta racionalidad, la práctica social estará determinada por unos acontecimientos conversacionales, desde los cuales se configuran significados en conjunto, re-creándose y reproduciéndose en la individualidad de las personas; concepto que se define como Acción Conjunta desde el cual se dan los procesos de construcción social; así, como flujo de interacciones, la acción humana se da sobre la base del significado que los eventos tienen para los actores y los significados se manejan y modifican a través de un proceso interpretativo consustancial a la interacción.

En cuarto lugar, pese a definirse la práctica social desde las significaciones imaginarias sociales, la naturaleza de su definición es multidireccional, pues en la racionalidad magmática un campo social es origen, pero a la vez es originado, con lo cual se permea su naturaleza desde los niveles de relación y se supera la racionalidad causal.

Esta consideración es de gran valor a la hora de afrontar los estudios sobre las prácticas sociales, pues su naturaleza no corresponde a la racionalidad causa-efecto y por tanto buscar su control y dominio es poco probable (Habermas). Las prácticas sociales al estar inmersas en esas dimensiones simbólicas que organizan las formas de ser/hacer, decir/representar no pueden estar sujetas a una ciencia técnica que busque incondicionalmente su control y dominio, pues al no seguir una lógica uni-direccional, en el camino de su configuración, establece relaciones diversas, por tanto su reconocimiento es más factible desde 
aquellas ciencias que buscan la comprensión sociohistórica (ciencias crítico-sociales) y transformacional o emancipatoria (ciencias críticas y de la acción).

Esta misma naturaleza dinámica y multidimensional de la práctica social hace que su manifestación se encuentre situada en las representaciones sociales, en cuyo trasfondo está la expresión del ser social y psicosomático. Al considerar que los imaginarios sociales son, en realidad, esas motivaciones, convicciones y creencias/fuerza que llevan a las sociedades a generar acuerdos y sancionarlos como válidos en las acciones e interacciones de dichas sociedades. Las prácticas no solo son generadas desde lo social, sino que son generadoras de dinámica social, son la fuerza que hace que estos acuerdos sobre cómo debe ser o no una práctica, se respeten y cumplan. De ahí que cuando estas motivaciones, convicciones y creencias/fuerza se transforman, los acuerdos también cambian y se generan nuevas dinámicas sociales, nuevas prácticas sociales, e incluso nuevas sociedades. Desde estos acuerdos sancionados, las sociedades efectivamente crean los dispositivos para que ellos se puedan llevar a cabo en un proceso de reconfiguración permanente devenido de la búsqueda constante de una esencia de humanidad conjunta.

En síntesis, las prácticas sociales no se dan aisladas de las formas de concebir las realidades, de las convicciones y creencias que sobre esta se tienen, de las significaciones imaginarias sociales que las comunidades han configurado. Por el contrario, son estas significaciones las que orientan la definición de las dinámicas funcionales de lo social y en ellas, los dispositivos para que estos acuerdos funcionales sean posibles. Lo social es coexistencia; coexistencia de lo psicosomático y de lo social, de lo ensídico y lo imaginario, de la significación y la función, del ser/hacer (theukhein social y del decir/representar (Legein social). Por eso Castoriadis asume que lo social: "no puede ser pensado con la lógica heredada, lo que quiere decir que no podemos pensarlo como conjunto determinable de elementos perfectamente distintos y bien definidos. Hemos de pensarlo como un magma, e incluso como un magma de magmas, con lo que no quiero decir el caos, sino el modo de organización de una diversidad no susceptible de ser reunida en un conjunto, ejemplificada por lo social, lo imaginario o lo inconsciente" (Castoriadis 1989:34). Esta particularidad es reconocida por Moscovici y Jodelet, cuando consideran que las representaciones sociales desde las cuales se generan las prácticas sociales están ancladas en una gran base imaginaria.

En esta consideración, las personas generan representaciones de la realidad desde los acuerdos sancionados socialmente, pero las matizan con sus particularidades, esto es lo que hace, en primer lugar, que las prácticas sociales no sean siempre iguales, pese a mantener algunas generalidades. En segundo lugar, que ellas generen nuevas formas de ver el mundo (nuevos imaginarios sociales) y en tercer lugar que se generen nuevas prácticas a veces rompiendo con las hegemonías naturalizadas en el mundo de la vida cotidiana.

Lo anterior implica que una práctica social no cambia porque se transforme la representación sobre algo o alguien; ella se transforma fundamentalmente porque la fuerza que la hacía posible se transformó. Recordemos que la representación social es siempre, tal y como lo afirman Jodelet, representación de algo, es presentar de otra forma y esa forma que toma la representación siempre tendrá como base un imaginario social. En un ejemplo de Michael Gilly (citado en Moscovici 1986:608) sobre la representación, las clases sociales y el éxito escolar, muestra cómo la escuela representa para las clases menos favorecidas "una esperanza de promoción social por medio del saber" en cuyo caso, son todas las redes de sentido que se tejen en torno a la escuela; las convicciones, motivaciones y creencias/fuerza sobre el papel de la evaluación, de los maestros de la sociedad, de los mismos estudiantes o sobre las dinámicas del mundo, las que configuran el imaginario social. Gracias a estas y sus particularidades, se configura una representación social de este tipo, que lleva a que se generen acuerdos sociales sobre las formas de ser 
en la Escuela y ser la Escuela, hacer en ella y hacerla, de decir la Escuela y decir en la escuela y de representarla. O sea, no es la representación o la actividad, las cuestiones centrales de la práctica social; pues las representaciones tienen como base las significaciones imaginarias sociales, y las actividades son acciones de la sociedad $\mathrm{o}$ de las entidades psicosomáticas realizadas desde esos marcos representacionales que empujan a que ellas se realicen de una o de otra forma; es la motivación / convicción / creencia fuerza que las sociedades configuran sobre el mundo, la vida y la muerte, lo que lleva a esta o aquella representación sobre la Escuela y desde la cual se genera la práctica social.

En esta dimensión de la práctica social (en la dimensión representacional) las posibilidades de validez son descifradas por Jodelet cuando asumen que ella se configura en el marco de su posibilidad de reconocimiento y práctica social. Se considera como tal cuando una experiencia está suficientemente objetivada; esto es, cuando tiene repercusiones profundas en cada uno de los actores sociales del grupo que la ha configurado, logrado generar una imagen relativamente clara sobre el asunto. $O$ sea, cuando las prácticas sociales corresponden a un orden de ideas que se reconoce como normalizado, desde el cual se inspiran dichas prácticas. Pero, en palabras de los autores en mención, la representación también debe responder a un anclaje social; esto es que esté presente en la gran mayoría de los actores sociales que definen dicha representación. El nivel de anclaje estaría determinado por la fuerza social de la representación y con ello la regularidad social de la práctica realizada.

En el escenario de lo dicho, la práctica social es mucho más que la realización de una mera actividad mecánica, por cuanto la acción misma del ser humano expresa la conjugación de creaciones sociohistóricas que han ido dando forma socialmente sancionada; formas que trasforman a la vez a quienes la sancionan. Entonces la práctica social, es expresión de la trasformación constante del mundo, en la cual, el ser humano por ser en el mundo, al transformarlo se ve trasformado por sus trasformaciones. Cuando se realiza una práctica social se está justamente poniendo de manifiesto, a la vez y para siempre, las múltiples trasformaciones que en la historia y la tradición el ser ha ido elaborando hasta consolidar la acción realizada como práctica social; por tanto, la práctica social expresa la primacía de la fuerza sociohistórica como trasformación constante; como expresión más fuerte de los imaginarios instituidos; de aquellas convicciones, creencias y motivaciones fuerza que se han ido consolidando y han ido consolidando una forma particular de realizar la práctica. Lo anterior porque el imaginario social es siempre transformación y expresa movilidad, así sea imaginario instituido, manifiesta la movilidad sociohistórica que lo llevó a consolidarse desde la sanción social como acuerdo sobre la mejor o peor forma de ser/hacer y decir/representar en-el-mundo.

Pero estas trasformaciones no podrían serlo sin la fuerza de creación radical del ser psicosomático, que es quien genera la creación. La fuerza primera del imaginario radical es, en esta racionalidad, la fuente de movilidad del mundo. Por tanto, ese imaginario radical sobre una práctica determinada, que comienza a ser psicosomático, logra fuerza instituyente cuando se proyecta como realización social y busca consolidarse como práctica socialmente sancionada. Lo anterior en consideración a que las prácticas sociales no salen de la nada, surge del esfuerzo creativo de los sujetos particulares (entidades psicosomáticas) que, al proyectarla con miras a la realización social, se llena de fuerza instituyente y comienza a hacer parte del colectivo anónimo como fuerza sancionada, como convicción y creencia. En este trascurso, la misma práctica se puede modificar al modificar a quienes la consideran suya.

Entonces, una práctica social no puede ser considerada como creación social exclusiva ni como creación de sujetos particulares, pues ellos mismos ya están impregnados de lo social para configurarse como tales; es producto y productora de relaciones fuertemente imbricadas entre lo social y lo particular y por tanto 
expresión de lo que el ser humano es, como entidad social y psicosomática. Esto es, expresión de trasformación y creación humana.

Es evidente que en estas múltiples e imbricadas relaciones se funden de forma constante lo particular del ser humano con el saber social; sus dimensiones lingüísticas, comunicativas, cognitivas, biológicas, políticas, éticas o estéticas, en cuya movilidad se va consolidando la creación como propiedad exclusivamente humana. En el acto creativo se funde la particularidad (ya socializada) con ese saber del colectivo anónimo para constituir todo lo que el ser humano es. Por tanto, la práctica social, además de ser expresión de lo social y lo psicosomático, es la expresión de la multidimensionalidad del ser humano, esto es, expresión de la humanidad del ser humano.

\section{Conclusiones}

Reconocer la práctica social es reconocer el ser humano que la desarrolla, pues en ella se esboza la fuerza de las significaciones imaginarias sociales que hacen generar representaciones en el marco de las cuales se definen las acciones e interacciones humanas; por tanto, una práctica social no puede reducirse a una actividad, pues ella no es más que el producto realizativo de un cúmulo de convicciones / motivaciones y creencias fuerza que la orientan. No implica que esas convicciones / motivaciones y creencias sean meras fuerzas sociales que desde afuera inducen al sujeto a actuar de una u otra forma, pues, ellas son a la vez, fuerzas sicosomáticas que configuran dichas manifestaciones.

Por eso lo que pervive en el ethos de fondo de una práctica social es el reflejo de una multiplicidad compleja de entramados y relaciones que van desde los intereses particulares, los saberes, las reflexiones, las dotaciones biológicas hasta las pre-disposiciones sociales, las que articuladas a manera de nudo de Borromeo, generan unas significaciones imaginarias sociales desde las cuales se propician representaciones que son esbozadas en la práctica social.

Pero, así como esta realización no se da de forma unidimensional, tampoco lo hace de forma unidireccional, pues desde la racionalidad de los imaginarios sociales, no es de coherencia que primero se dé la experiencia para que ella sea significada o que primero se dé la significación para que ella sea experienciada, puesto que la experiencia es generativa de significación imaginaria social pero también lo imaginario es generativo de experiencia social. La base de esta consideración está lícitamente argumentada desde la racionalidad magmática que tiñe las dinámicas de lo imaginario social: en ella, la fusión de los horizontes no es una perspectiva teleológica sino una constante en la vida social y humana, en tanto es desde esta dinámica que se configuran las realidades de lo social y la misma sociedad, en un proceso de constante ebullición y emergencia que hace ver los acuerdos sociales como algo transitorio.

En una práctica social se funde irreductiblemente y en todo momento la experiencia y la imaginación, el cuerpo y la razón, la historia y la fuerza radical de la creación psicosomática. Aunque en las realidades sociales las dimensiones ensídica y racional del mundo son subordinadas a la dimensión imaginaria social, también se funden indefectiblemente como un magma, para generar los acuerdos sociales sobre esas formas de ser/hacer, decir/representar la vida social; por ello, la práctica social esboza significación, pero también objetivación y anclaje social porque es a la vez, producto de los imaginarios sociales y de sus representaciones. 


\section{Patrocinio}

Artículo derivado del proyecto de investigación "Habitar la ciudad desde las prácticas de formación para la investigación en San José de Cúcuta", con la participación de los grupos de investigación Grupo Mundos Simbólicos, Grupo Desarrollo Humano, Educación y Procesos Sociales y Grupo Educación, Ciencias Sociales y Humanas; como subproyecto del macroproyecto correspondiente al segundo núcleo del programa "Escuela dinámica para la construcción de paz, equidad y reconciliación en el posconflicto", desarrollado en colaboración por Universidad de Caldas, Universidad Católica de Manizales, Universidad Surcolombiana, Universidad Simón Bolívar sede Cúcuta, Universidad del Cauca, Universidad Tecnológica y Pedagógica de Tunja, Universidad de la Amazonía y Universidad Manuela Beltrán de Bogotá.

\section{Nota}

(1) La dimensión ensídica es una categoría utilizada por Castoriadis para referirse a una forma de organización del mundo en la cual prima lo sustancial, todo aquello que puede organizarse según la lógica de los conjuntos. Esta categoría también es reconocida por el autor como dimensión ensídica del mundo. En su perspectiva compleja de las realidades sociales, esta dimensión es subsumida por la dimensión imaginaria, sin la cual es imposible intelegir el mundo ensídico. El lenguaje es código gracias a la dimensión conjuntista, pero es imposible sin la dimensión significativa, desde la cual se define el lenguaje como lengua, como forma de comunicación social. Así mismo, cualquier hacer/ser en el mundo social, es inseparable de su significación (Castoriadis 1998:165).

\section{Bibliografía}

Abric, J.C. 2001. Prácticas sociales y representaciones sociales. México: Ediciones Coyoacán.

Arribas, S. 2008. Cornelius Castoriadis y el imaginario político. Foro Interno (8): 105-132.

http://revistas.ucm.es/index.php/FOIN/article/viewFile/FOIN0808110105A/7870

Baeza, M.A. 2000. Los caminos invisibles de la realidad social. Santiago: Ril editores.

Bourdieu, P. 2007. El sentido práctico. Buenos Aires: Siglo XXI Editores.

Camacho, A. 2006. Socioepistemología y prácticas sociales. Educación Matemática 18(1): 130-160.

http://www.redalyc.org/pdf/405/40518106.pdf

Castoriadis, C. 1998. Hecho y por hacer. Buenos Aires: Eudeba.

Castoriadis, C. 1989. La institución imaginaria de la sociedad (vol.2). Barcelona: TusQuets.

Castoriadis, C. 1983. La institución imaginaria de la sociedad (vol. 1). Barcelona: TusQuets.

Castro, P. et.al. 1996. Teoría de las prácticas sociales. Complutum 2 (6): 35-48.

http://revistas.ucm.es/ghi/11316993/articulos/CMPL9696330035A.PDF

Centro de Estudios de Políticas y Prácticas en Educación. 2009. Prácticas de liderazgo directivo y resultados de aprendizaje. Hacia conceptos capaces de guiar la investigación empírica REICE 7(3): 19-33. http://www.redalyc.org/articulo.oa?id=55114063003

Foucault, M. 2002. Arqueología del saber. Buenos Aires: Siglo XXI editores

Gadamer, H.G. 1998. Verdad y método II. Salamanca: Ediciones Sígueme.

Gadamer, H.G. 1993. Verdad y Método I. Salamanca: Ediciones Sígueme. 
Grupo Universidad de Granada. 2015. Qué es la práctica social. Aula de sistematización de la práctica social. Blog post http://aula.tcomunica.org/?page_id=40

Heidegger, M. 1977. El ser y el tiempo. México: Fondo de Cultura Económica.

Jäger, S. 2003. Discurso y conocimiento: aspectos teóricos y metodológicos de la crítica del discurso y del análisis de dispositivos. En: R. Wodak y M. Meyer. Métodos de análisis crítico del discurso, p. 61-94. Barcelona: Editorial Gedisa.

Jaramillo, J. 2012. Representaciones sociales, prácticas sociales y órdenes de discurso. Una aproximación conceptual a partir del análisis crítico del discurso. Entramado 8(2): 124-136.

http://www.redalyc.org/articulo.oa?id=265425848008

Latorre, C. et.al. 2009. Las prácticas sociales desde la carrera de odontología. Investigación en Enfermería: Imagen y Desarrollo 11(2): 93-105. http://revistas.javeriana.edu.co/index.php/imagenydesarrollo/article/viewFile/1619/1041

Moscovici, S. 1986. Psicología social II. Barcelona: Paidós.

Murcia, N. 2011. Imaginarios sociales. Preludios sobre Universidad. Saabrüchen: Eae editores.

Pintos, J.L. 2002. El metacódigo relevancia y opacidad en la construcción sistémica de las realidades. RIPS: Revista de investigaciones políticas y sociológicas 2(1-2): 21-34.

Rodrigues Leite da Silva, A. et.al. 2012. A constructionist approach for the study of strategy as Social practice. BAR. Brazilian Administration Review 9: 1-18. doi: 10.1590/S1807-76922012000500002

Schutz, A. 2008. El problema de la realidad social. Buenos Aires: Amorrortu.

Shotter, J. 2001. Realidades conversacionales: la construcción de la vida a través del lenguaje. Buenos Aires: Amorrortu.

Theunissen, M. 2013. El Otro. Estudios sobre la ontología social contemporánea. México: Fondo de Cultura Económica.

Tylor, C. 2006. Imaginarios sociales modernos. Barcelona: Paidós.

Yogo, F. 2003. Magma: Cornelius Castoriadis. Buenos Aires. Biblós.

Recibido el 18 May 2016

Aceptado el 4 Ago 2016 